University of Nebraska - Lincoln

DigitalCommons@University of Nebraska - Lincoln

Publications, Agencies and Staff of the U.S.

Department of Commerce

U.S. Department of Commerce

$1-2009$

\title{
Movements and Diving Behavior of Pelagic Spotted Dolphins
}

\author{
Michael Scott \\ Inter-American Tropical Tuna Commission, Scripps Institution of Oceanography, La Jolla, California
}

Susan Chivers

Southwest Fisheries Science Center, NOAA Fisheries

Follow this and additional works at: https://digitalcommons.unl.edu/usdeptcommercepub

Part of the Environmental Sciences Commons

Scott, Michael and Chivers, Susan, "Movements and Diving Behavior of Pelagic Spotted Dolphins" (2009). Publications, Agencies and Staff of the U.S. Department of Commerce. 46.

https://digitalcommons.unl.edu/usdeptcommercepub/46

This Article is brought to you for free and open access by the U.S. Department of Commerce at DigitalCommons@University of Nebraska - Lincoln. It has been accepted for inclusion in Publications, Agencies and Staff of the U.S. Department of Commerce by an authorized administrator of DigitalCommons@University of Nebraska - Lincoln. 
MARINE MAMMAL SCIENCE, 25(1): 137-160 (January 2009)

No claim to original US government works

DOI: $10.1111 / \mathrm{j} .1748-7692.2008 .00241 . x$

\title{
Movements and diving behavior of pelagic spotted dolphins
}

\author{
Michael D. SCOTT \\ Inter-American Tropical Tuna Commission, \\ Scripps Institution of Oceanography, \\ La Jolla, California 92037, U.S.A. \\ E-mail: mscott@iattc.org \\ Susan J. Chivers \\ Southwest Fisheries Science Center, \\ NOAA Fisheries, \\ P. O. Box 271, La Jolla, California 92038, U.S.A.
}

\begin{abstract}
We radio tracked 20 pantropical spotted dolphins (Stenella attenuata) in the pelagic waters of the eastern tropical Pacific Ocean during three research cruises in 1992, 1993, and 2001. Dolphins were tracked for up to $6 \mathrm{~d}$ from 20 to $1,000 \mathrm{~km}$ offshore. Seventeen of these dolphins also carried time-depth recorders, nine of which were recovered with a combined total of $477 \mathrm{~h}$ of dive data. The movement data suggested that the dolphins associate with areas of relatively high biological productivity. Dolphins close to shore moved along the continental slope, while some dolphins traveled farther offshore along thermocline "ridges." Tracking and tagging multiple dolphins demonstrated the dynamic nature of dolphin herds, which change size and membership over the course of a day. At night, the dolphins traveled more slowly but dove deeper and longer, with more rapid ascents and descents than during daylight hours. These nighttime dive characteristics support the hypothesis suggested by some food habit studies that spotted dolphins are nocturnal feeders. Comparison of dive data with acoustic backscatter data indicates that spotted dolphins typically begin and end nighttime feeding activities with dusk and dawn diving bouts that track the vertical migration of organisms associated with the deep scattering layer.
\end{abstract}

Key words: radio tracking, diving, feeding, spotted dolphin, Stenella attenuata, purse-seine fishery, eastern tropical Pacific Ocean, ETP.

The pantropical spotted dolphin (Stenella attenuata) is largely a pelagic species distributed worldwide in tropical waters. In the eastern tropical Pacific (ETP), spotted dolphins frequently associate with yellowfin tuna, Thunnus albacares, a fact that tuna purse-seine fishermen have taken advantage of to locate and capture the tuna. Although incidental dolphin mortalities in the fishery are relatively low (IATTC 2004), high mortalities in the past led to extensive studies on spotted dolphins 
and research continues to focus on distribution and stock structure, estimation of abundance, fishery mortality and dolphin life history, ecology, and behavior, and gear modifications to reduce mortality in tuna purse-seine nets. While the spotted dolphin in the ETP has become the best-studied pelagic dolphin, studying pelagic dolphins is inherently difficult, and we still know little about what influences their daily movements, how are herds structured, when they forage, and what they do underwater.

There are two ecotypes in the ETP: the pelagic forms (the northeastern and southern/western offshore stocks) and the coastal subspecies ( $S$. a. graffmani) found within $130 \mathrm{~km}$ offshore (Dizon 1994). The pelagic ecotype is broadly distributed in the ETP and its distribution and density have been correlated with broad-scale environmental features. A shallow thermocline dominates this region, and dolphin densities are particularly high along the $10^{\circ} \mathrm{N}$ divergence zone, associated with thermocline "ridging" and high productivity (Au and Perryman 1985, Reilly 1990, Ballance et al. 2006). This area also coincides with the heart of the tuna purseseine fishery. We also know from tagging and radio-tracking studies that individuals travel $50-100 \mathrm{~km} / \mathrm{d}$ and may range over $2,400 \mathrm{~km}$ or more during the course of 9-10 mo, which suggests a seasonal east-west migration (Leatherwood and Evans 1979; Leatherwood and Ljungblad 1979; Butler and Jennings 1980; Perrin et al. 1979, 1985).

From long-term data collected by observers aboard tuna seiners and research boats, we know that spotted dolphin herds are typically large, frequently containing hundreds or even thousands of animals, and that spotted and spinner dolphins (S. longirostris) frequently form mixed-species herds. Dolphin herds are dynamic, changing in size and species composition throughout the day (Scott and Cattanach 1998).

From food habits studies we know that spotted dolphins are generalist feeders on epipelagic and mesopelagic fish and squids. Some authors suggest that spotted dolphins feed primarily on epipelagic prey (Perrin et al. 1973, Norris and Dohl 1980), while others suggest they also feed on vertically migrating prey (e.g., myctophids and mesopelagic squids) that are associated with the deep scattering layer (DSL) when it comes to the surface at night (Shomura and Hida 1965, Fitch and Brownell 1968, Robertson and Chivers 1997, Fiedler et al. 1998). Because of these differences in prey found in spotted dolphin stomachs, some authors have suggested that spotted dolphins are diurnal feeders (Norris and Dohl 1980; Au and Pitman 1988), while others suggest that they are nocturnal (Robertson and Chivers 1997, Fiedler et al. 1998, Scott and Cattanach 1998, Baird et al. 2001).

We know very little about the diving behavior of pelagic dolphins. The evolution of smaller and more memory-packed time-depth recorders (TDRs) during the 1990s however, have provided detailed dive histories for several free-ranging small delphinids. One of these studies used suction cups to attach TDRs to spotted dolphins off Hawaii (Baird et al. 2001) and another used satellite tags to monitor dives of Atlantic spotted dolphins, $S$. frontalis, off Texas (Davis et al. 1996). The suction-cup attachments used on the Hawaiian spotted dolphins provided only a few hours of data per track, but revealed deep diving, to over $200 \mathrm{~m}$, in association with the vertical ascent of DSL organisms after sunset. The data from the satellite-tagged Atlantic spotted dolphin were binned by depth and time and revealed no diel pattern in diving. The deepest dives, of 40-60 m, were deep enough to reach the relatively shallow bottom of the continental shelf. 
As part of research studies on the tuna-dolphin bond and on the effects of fisheryinduced stress on dolphins, we attached radio tags and TDRs on spotted dolphins in the ETP. The radio-tracking data, in conjunction with oceanographic sampling, could help determine whether the movements of pantropical spotted dolphins in the pelagic environment were associated with finer scale oceanographic features. Monitoring multiple tagged dolphins simultaneously allowed us to examine the stability of individual associations within herds, and deploying TDRs allowed us to examine dive characteristics and determine when and how deep the dolphin foraged. The movement and diving patterns from this study would allow comparison between spotted dolphins from pelagic habitats and those from island and continental shelf habitats.

\section{METHODS}

Three cruises were conducted aboard the NOAA ship, R/V McArthur (54 m long) in conjunction with chartered commercial tuna purse seiners (54-70 m long). In 1992, a 30-d cruise was conducted during 6 November-5 December 1992 in an area $200-1,000 \mathrm{~km}$ off the coast of Central America where the seas were likely to be relatively calm. A second 30-d cruise was conducted on the same dates in 1993 in an area $20-400 \mathrm{~km}$ off the coast of central Mexico where, again, the seas were most likely to be calm. A third 58-d cruise was conducted during 8 August-4 October 2001 about 200-750 km south of the southern coast of Mexico (Fig. 1).

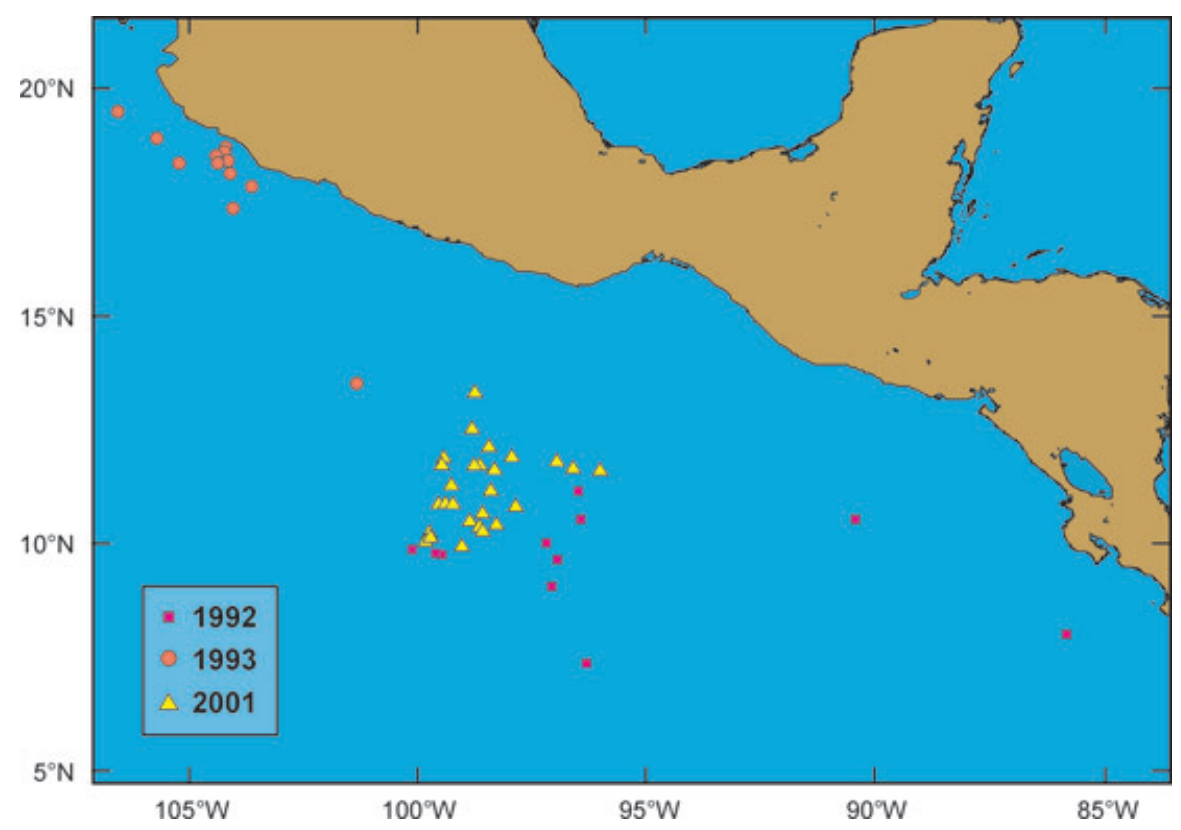

Figure 1. Study areas during 1992, 1993, and 2001 showing locations of purse-seine sets and dolphin captures. 

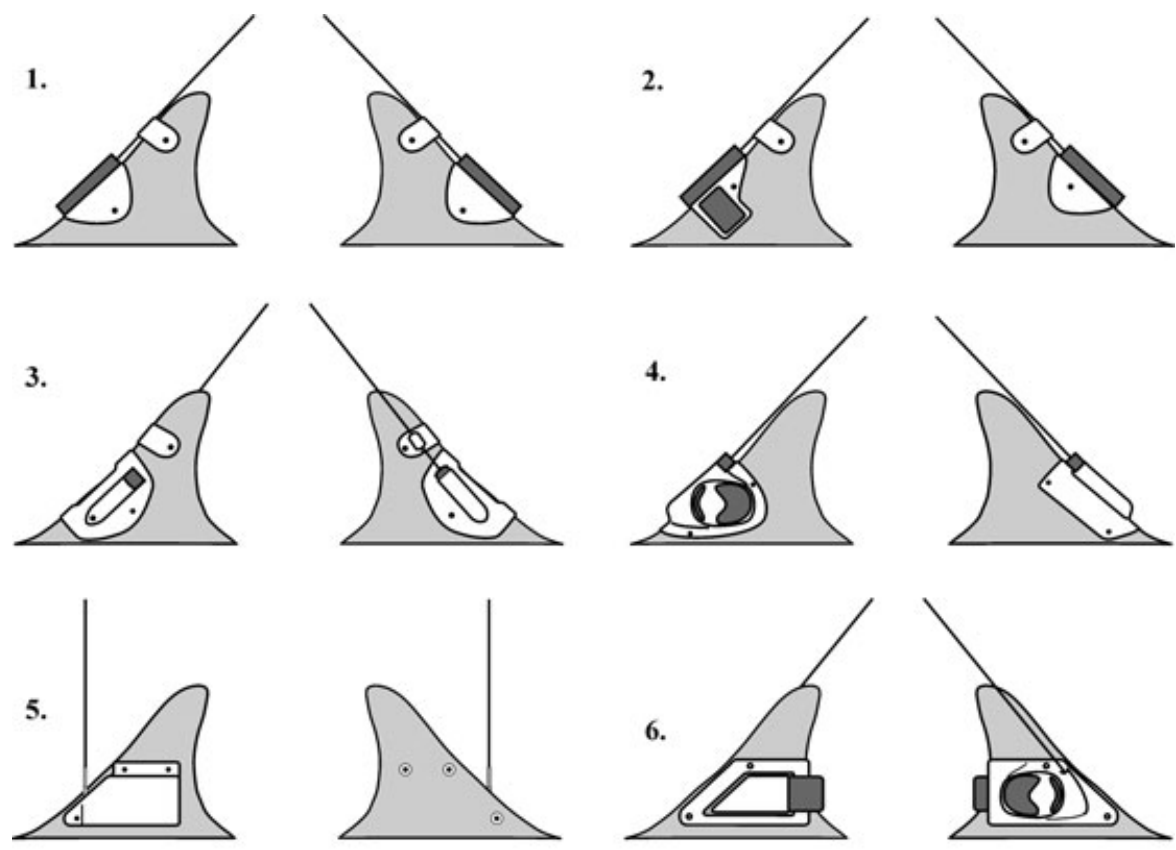

7.

\section{बृ}

8.

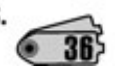

Figure 2. Tag types used during the tracking studies. Type 1: high-power transmitter used in 1992-1993, Type 2: high-power transmitter with a Mk-5 TDR used in 1992-1993, Type 3: high-power transmitter with a Mk-7 TDR used in 2001, Type 4: high-power transmitter with a Mk-8 TDR used in 2001, Type 5: satellite transmitter used in 2001, Type 6: low- or high-power transmitter with a Mk-8 TDR and a thermal data logger, Type 7: "bullet" tag with a low-power transmitter and flexible antenna, and Type 8: Dufflex visual tag.

\section{Capture and Tagging Methods}

Spotted dolphin herds were encircled by the purse seiner's net (see Coe and Sousa 1972 , for a description of the purse-seining process). Most were pure spotted dolphin herds, but some were mixed-species herds containing spinner dolphins, common dolphins (Delphinus delphis), or bottlenose dolphins (Tursiops truncatus). During the 1992 and 1993 tuna-dolphin association studies, the dolphins were typically caught with yellowfin tuna, but during the 2001 dolphin-stress study, they were usually not captured together.

After the dolphins were encircled, the bottom of the net pursed, and two-thirds of the net rolled on deck, individual dolphins were captured as they swam in the net circle by a team of swimmers and placed in partially flooded rafts. Focal dolphins were outfitted with high-power radio transmitters (Model MOD-050-HP with a TA6H semi-rigid, stainless steel antenna, $148 \mathrm{MHz}$ : Telonics, Mesa, AZ) mounted on expanded-PVC (1992-1993; Fig. 2, Types 1 and 2) or molded-polyethylene (2001; Fig. 2, Types 3 and 4, Fig. 3) plastic saddles (Trac Pak, Fort Walton Beach, FL). 


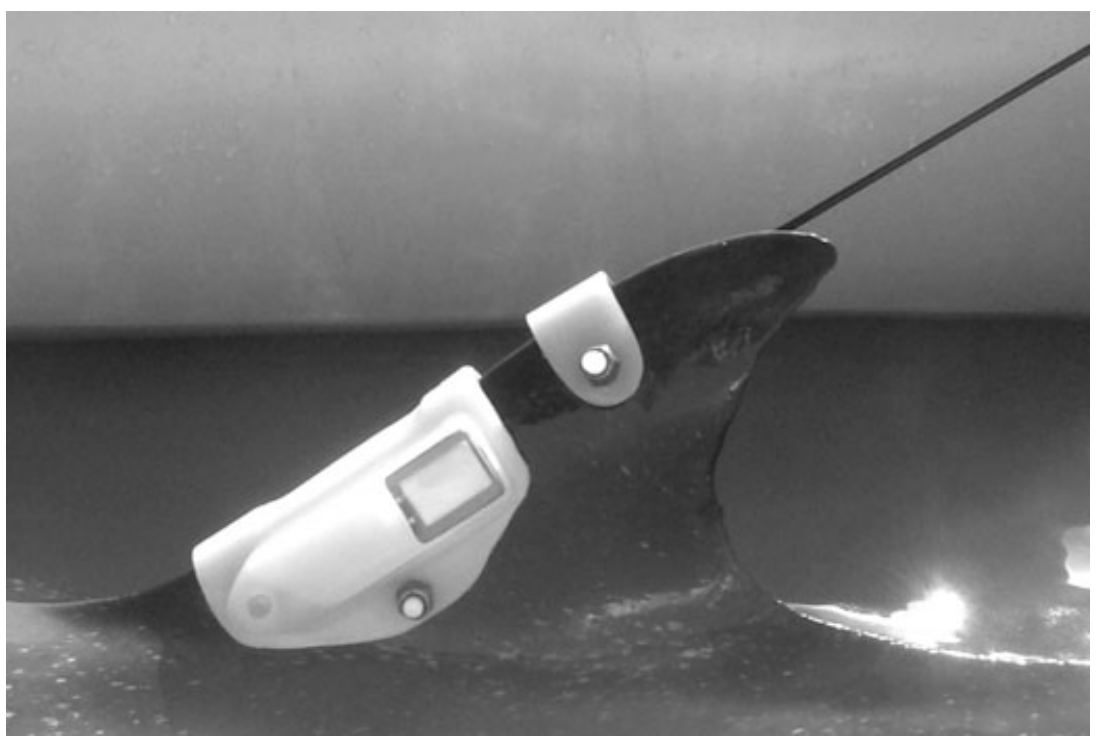

Figure 3. Spotted dolphin radio-tagged with a high-power transmitter (far side of package, with antenna extending above dorsal fin) and a Mk-7 TDR (inserted in pocket on near side of package) used in 2001 (Type 3 in Fig. 2). Two Delrin pins and magnesium nuts secured the package until it was removed or the magnesium nuts corroded.

The saddles were padded on the inside with neoprene (1992-1993) or a bilayer of 2-mm Blue Poron and 2-mm Blue Puff (2001) used in human prosthetic devices to reduce skin irritation. The saddles were attached to the dorsal fin with two or three $1 / 4$-in. $(0.64-\mathrm{cm})$ Delrin pins. The Delrin pins were secured by magnesium nuts that corroded in sea water, releasing the package within a few days or weeks. The transmitters were designed to provide maximum range, relatively long signals $(30 \mathrm{~ms})$, and a frequent transmission rate $(2 / \mathrm{s})$, all at the expense of longevity (conservatively estimated to be about $2 \mathrm{wk}$ ).

We also attached TDRs (Models $\mathrm{Mk}$ 5, Mk 7, and Mk 8: Wildlife Computers, Woodinville, WA) to most of the high-power transmitter packages (Fig. 2, Types 2,3 , and 4). The TDRs recorded the time and depth of the package every $10 \mathrm{~s}$ during 1992, every 5 s during 1993, and every second during 2001. They also had different depth ranges and resolutions; the Mk-5 TDRs used in 1992 measured depths up to $500 \mathrm{~m}$ with 2-m resolution, the Mk-5 TDRs used in 1993 measured depths up to $250 \mathrm{~m}$ with $1-\mathrm{m}$ resolution, and the Mk-7 TDRs measured depths up to $500 \mathrm{~m}$ with $0.25-\mathrm{m}$ resolution. Recovery of the TDRs required recapture of the dolphins to remove the packages. Data loggers that measured time, depth, velocity, skin temperature, and heat flux (Westgate et al. 2007) were also deployed in 2001 (Fig. 2, Type 6), but these data were collected for another study on thermoregulation and only movement and resighting data were included here.

Small, low-power transmitters (Model MOD-040 with a flexible, multistranded stainless steel antenna, $148 \mathrm{MHz}$ : Telonics, Mesa, AZ) and visual tags were attached to the rear edge of the dorsal fin to identify the dolphins caught in association with the focal dolphins on subsequent sets (Fig. 2, Types 7 and 8). The visual tags we used were 
Jumbo Rototags (Dalton, Nettlebed, England) and Dufflex tags (sheep/goat model with an antibacterial coating on the pin, Destron Fearing, South St. Paul, MN); these tags are not designed to come off, but retention time is typically short as the tags are frequently shed (Scott et al. 1990). The low-power transmitters were encased in hydrodynamic polyethylene plastic capsules ("bullet tags": Trac Pak, Fort Walton Beach, FL) and attached with Dufflex tag pins from which the tag flaps had been cut away. Satellite transmitters were also attached (Fig. 2, Type 5; models SDR-T16 and SPOT-2, Wildlife Computers, Woodinville, WA), but for the purposes of this paper the satellite tags were considered to be visual tags; the long-term movements of these animals will be analyzed separately in another paper. All of the focal dolphins were spotted dolphins; dolphins tagged in association with the focal dolphins were also spotted dolphins, with the exception of two eastern spinner dolphins (S. longirostris orientalis). The two spinner dolphins were not resighted after being released and are not considered further in this paper.

The amount of time the dolphins spent in the raft for the tagging process lasted 3-18 min, depending on the type of tag applied and the number of blood samples taken. The length, sex, and color phase of the dolphins were recorded (see Perrin 1969 for description of ontogenetic color phases in spotted dolphins). In 1993, blood samples were also taken from the dolphins for analyses of stress, reproductive hormones, genetics, and health condition. In 2001, additional biopsy skin samples were added to the collection protocol for analyses of stress and genetics. The dolphins were typically released inside the net so that the entire herd could be released together (see Coe and Sousa 1972 for a description of backdown release procedure). The entire capture process (from net set to release of the dolphins) lasted, on average, $2.1 \mathrm{~h}$.

\section{Tracking Methods}

An array of four three- or four-element Yagi-Uda antennas, oriented at $90^{\circ}$ intervals, was mounted on the purse seiner, on the McArtbur, and, in 1992-1993, on the McArthur's two 9-m launches. The antenna arrays were mounted above the crow's nests of the purse seiners (about $22 \mathrm{~m}$ above the waterline) on the aft mast of the McArthur (about $17 \mathrm{~m}$ high), and on steel masts mounted on the launches (about $5 \mathrm{~m}$ high). The cables from each of the array's four antennas were connected to preamplifiers (to reduce signal loss) and then to a directional indicator (Advanced Telemetry Systems, Inc., Isanti, MN) linked to a receiver (Model TR-2 with a Model TS-1 scanner/programmer: Telonics, Mesa, AZ). This system sampled 5-ms segments of the signal from each of the antennas in sequence, allowing the signal strengths received by each antenna to be compared, and thus an approximate bearing from the vessel to be determined. A digital data processor (Model TDP-2: Telonics, Mesa, AZ) provided an approximate signal strength to obtain an estimate of distance to the transmitter. Even though signal strength is also a product of factors other than distance, calibration tests and triangulation of multiple bearings suggested that the signal strength could provide a reasonable estimate of distance. Prior to each cruise, we calibrated the signal strength recorded at a given gain setting against a floating test transmitter at a known distance from the McArthur and its tracking launches. Distances were checked when possible during daylight hours by observations from the McArthur's $20 \times$ binoculars (with calibrated reticles) and the purse seiner's helicopter. Positions that were outliers (requiring improbable speeds and course changes) were omitted.

During the tracking, care was taken not to affect the behavior of the animals. Most of the tracking was conducted from the McArthur at a distance of $4 \mathrm{~km}$ or greater 
from the focal dolphin, supplemented at times by one or both of the launches, the purse seiner, or its helicopter. The purse seiner and its helicopter usually approached the dolphins only when attempting to recapture them, however, and at other times was kept at a distance so as not to affect the dolphins' behavior.

When radio tracking from any of the vessels, the position, time, heading of the vessel, bearing to the dolphin, and signal strength were recorded every $15 \mathrm{~min}$. Speeds were calculated by summing the distances traveled in each hour. Caution should be taken in interpreting movement data from radio tracking, however, because the straight-line path assumed between plotted points can underestimate the actual distance traveled, and because any errors in the estimated positions of the dolphins will be reflected in the calculated speeds.

Surfacing times were also recorded for at least $15 \mathrm{~min}$ out of every hour when possible (radio signals were received only when the transmitter antenna cleared the surface of the water). Surfacing times and dive durations were also retrieved from the data loggers.

\section{Environmental Data}

A conductivity-temperature-depth (CTD) profiler (SEACAT SBE 19, Seabird Electronics Inc., Bellevue, WA) or an expendable bathythermograph (XBT) was deployed to $200 \mathrm{~m}$ from the McArthur approximately every $4 \mathrm{~h}$ to measure temperaturedepth profiles. The depth of the thermocline could then be compared with dolphin dive depths. The thermocline depth was defined as the $20^{\circ}$ isotherm (Kessler 1990). Observations of sea state, wind strength, and cloud cover were recorded hourly. In 2001 , the depth of the DSL was detected using a Simrad EQ-50 echosounder $(38 \mathrm{kHz}$, Horten, Norway). At this frequency, the echosounder detects mainly myctophids and euphausids in the DSL (Fiedler et al. 1998), but has little or no effect on dolphin behavior. ${ }^{1}$

\section{Analyses}

Both movement and dive data were stratified by time of day to compare daytime (0600-1800, local time) vs. nighttime (1800-0600) differences. The nighttime and daytime dive characteristics recorded by TDRs and the traveling speeds calculated from the radio-tracking positions were tested for significant differences $(\alpha=0.05)$ using a mixed-effects model with individual dolphins included as a random effect in the model. Data collected when the dolphins were being deliberately chased, when the seiner or its helicopter was nearby, or within $2 \mathrm{~h}$ after release from the net were excluded to remove the effects of seiner operations on dolphin behavior.

A computer program (Dive-analysis, Wildlife Computers, Woodinville, WA) extracted the following parameters from the dive histories stored on the TDRs: dive depth, dive duration, surface time, bottom time, ascent and descent rates, and a ratio of bottom time to dive depth. Dive depth was defined as the maximum depth of the dive. Dive duration was defined as the amount of time spent $\geq 5 \mathrm{~m}$ below the surface for more than $10 \mathrm{~s}$. The bottom time was defined as the amount of time spent within $85 \%$ of the maximum depth of the dive. Ascent and descent rates were

\footnotetext{
${ }^{1}$ Personal communication from T. Gerrodette, Southwest Fisheries Science Center, NOAA Fisheries, P. O. Box 271, La Jolla, CA 92038, May 2008.
} 
calculated as the maximum slope (in $\mathrm{m} / \mathrm{s}$ ) of the dive profile. For these analyses, only dive depths $\geq 5 \mathrm{~m}$ were used to eliminate the confounding factors of resolution $(2 \mathrm{~m}$ in $1992,1 \mathrm{~m}$ in 1993 , and $0.25 \mathrm{~m}$ in 2001) and swell height (typically $1-2 \mathrm{~m}$ during the cruises); this dive-depth cutoff is consistent with the definition adopted in another diving study of Hawaiian spotted dolphins (Baird et al. 2001).

\section{RESULTS}

\section{Tagging and Tracking Effort}

The study areas and capture locations are shown in Figure 1. During 1992, 10 sets on dolphins were made: six spotted dolphins were radio tagged, three of which also carried TDRs (two were recovered), and one spotted dolphin was visually tagged. During 1993, 18 sets were made: five spotted dolphins were radio-tagged, and four also carried TDRs (three were recovered). During 2001, 28 sets were made: 7 spotted dolphins were radio-tagged with high-power transmitters and TDRs (five recovered), 2 carried a thermal data logger (1 with a low-power transmitter and 1 with both a low- and a high-power transmitter; both recovered. See Westgate et al. 2007), 7 carried bullet tags with low-power transmitters, and 219 were visually tagged (including six satellite tags). The spotted dolphin herds captured were of the northeastern stock (Dizon et al. 1994).

The two-piece transmitter packages (Fig. 2, 3) appeared to provide good support for the antenna and produced strong transmissions. Close-range underwater and surface observations of the tagged dolphins in the net indicated that their swimming behaviors were no different from untagged dolphins. Twelve spotted dolphins were recaptured and their tags removed after 1-6 d. Field observations indicated that the tagged dolphins swam at the same speed as the rest of their herd mates during normal traveling and during chase by the purse seiners. However, even though tagged dolphins kept pace with the rest of the herd, they sometimes positioned themselves slightly behind the main group (within $100 \mathrm{~m}$ ), either by themselves or in subgroups of 2-12. Dolphin tooth marks on one saddle of D19 and tooth marks and a snapped transmitter antenna on D227 suggested that other dolphins had attempted to remove the packages in 2001, and that, perhaps, the tagged dolphins were keeping their distance from other dolphins to avoid this harassment. Short-term problems with tag attachment were not observed with the more rigid plastic saddles used in 19921993 , with the exception of one pin that had been positioned too close to the leading edge of the fin. The more flexible plastic saddles used in 2001 better conformed to the fin and were more hydrodynamic, but more care and experience was required to avoid overtightening of the nuts that could cause short-term pressure necrosis.

The radio-tracking system had a range up to $24 \mathrm{~km}$ from the McArthur and the purse seiner and at least $9 \mathrm{~km}$ from the launches. The dolphins typically did not appear to react to close approach (as close as $20 \mathrm{~m}$ ) by the tracking launches, nor did they avoid the McArthur when tracked from $4 \mathrm{~km}$ away or more. The dolphins increased their speed and aerial activity, however, whenever a purse seiner or its helicopter approached closely.

\section{Movements}

Twenty spotted dolphins were tracked for up to $6 \mathrm{~d}$ (Table 1). Six dolphins were tracked 650-1,000 km off the coast of Central America in 1992 (Fig. 4; the track of D6 is not included in the plot as it was interrupted after $2.5 \mathrm{~h}$ and not reinitiated due 


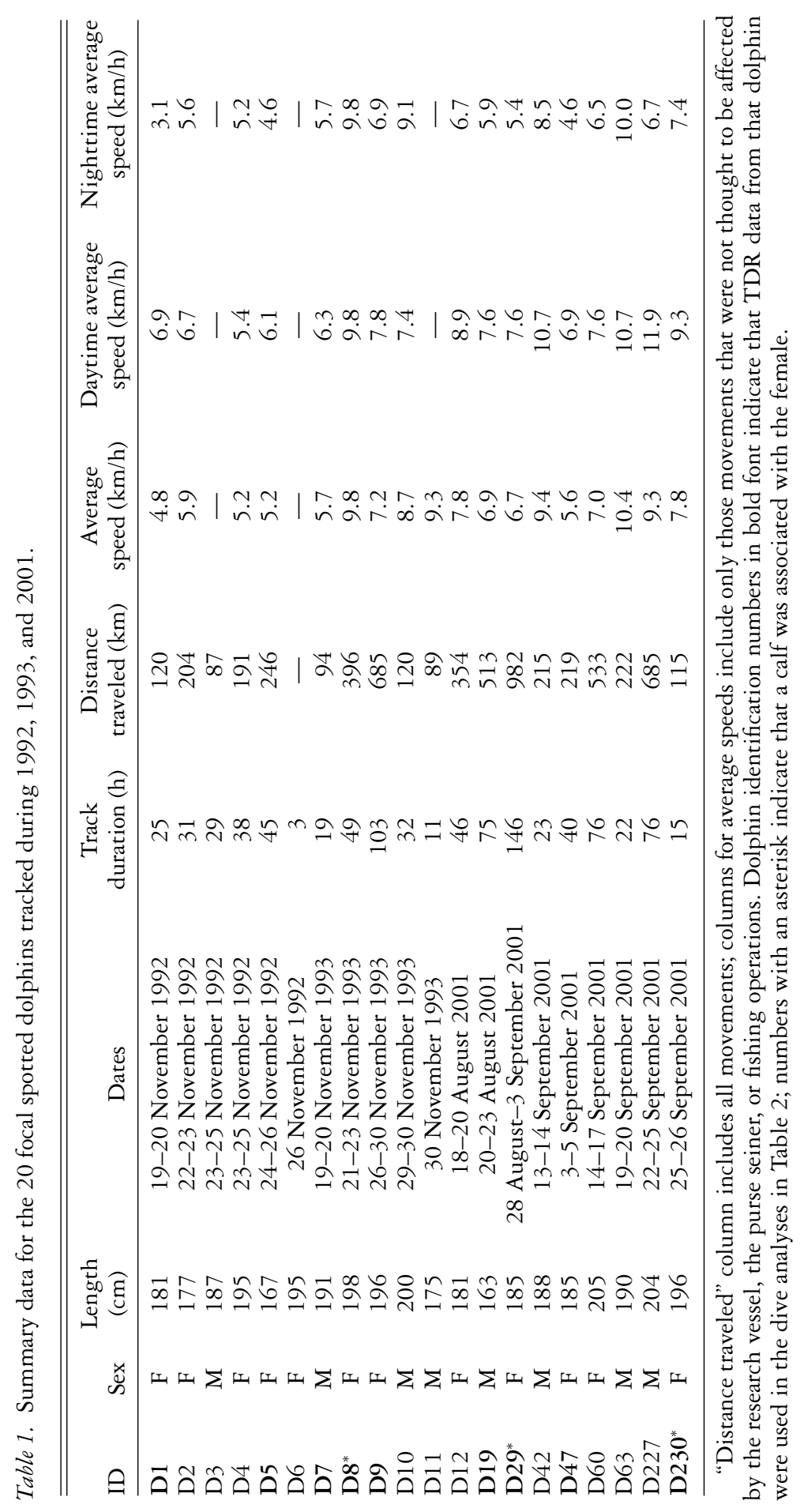




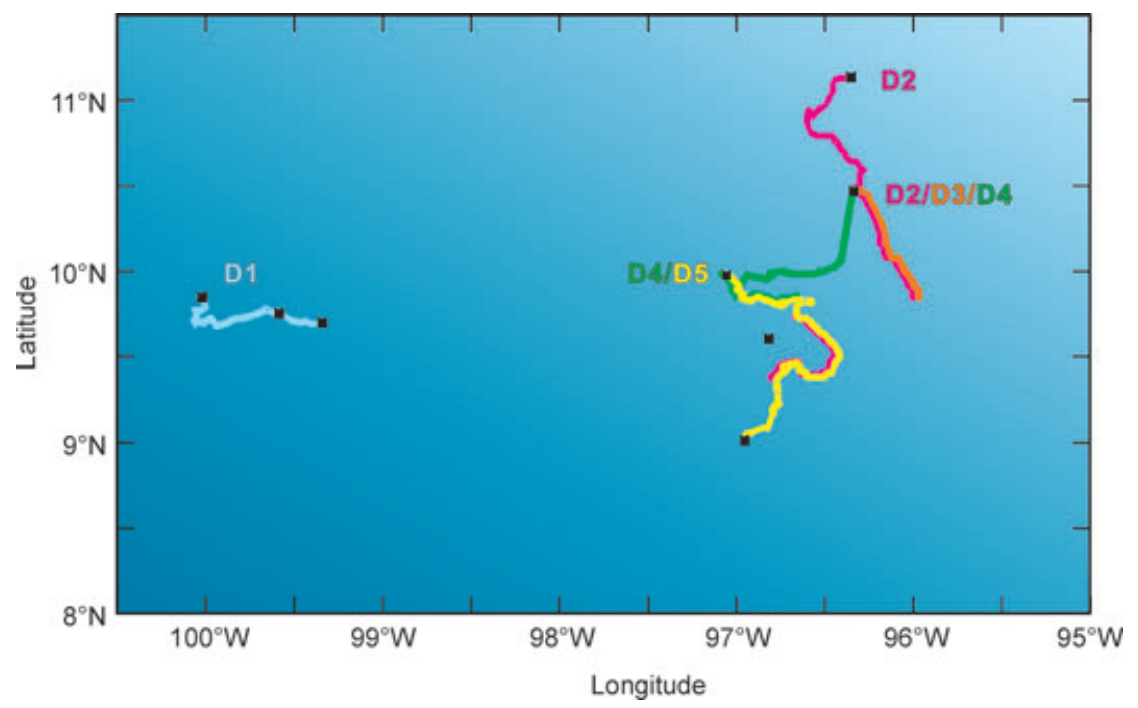

Figure 4. Movements of five dolphins (D1-D5) tracked during 1992. Squares represent locations of sets on dolphin herds. Water depths were in excess of 3,000 m; the depth of the thermocline ranged from $23 \mathrm{~m}$ to $33 \mathrm{~m}$.

to poor weather). Five dolphins were tracked within $170 \mathrm{~km}$ of the coast of central Mexico in 1993 (Fig. 5). Nine focal dolphins were tracked 200-750 km south of southern Mexico in 2001 (Fig. 6).

The dolphins traveled $111-248 \mathrm{~km}(60-134 \mathrm{nmi})$ per day (Table 1), with a mean swimming speed of $7.5 \mathrm{~km} / \mathrm{h}(4.0 \mathrm{kn}$ or $2.1 \mathrm{~m} / \mathrm{s})$. The dolphins swam significantly $(P<0.01)$ faster during the daytime, $8.6 \mathrm{~km} / \mathrm{h}(\mathrm{SD}=4.44)$, than during the nighttime, $6.6 \mathrm{~km} / \mathrm{h}(\mathrm{SD}=5.54)$.

The depth of the waters in the three study areas ranged from about 500 to $3,500 \mathrm{~m}$, and the depth of the thermocline was $23-33 \mathrm{~m}$ in $1992,25-56 \mathrm{~m}$ in 1993 , and 16-76 $\mathrm{m}$ in 2001. In 1993, the dolphins traveled along the continental slope (Fig. 5), where productivity would be high due to wind-driven upwelling (Bulgakov $e t$ al. 2005). In 2001, the study area coincided with the northern boundary of the North Equatorial Countercurrent (Wyrtki 1966) and most of the dolphin tracks followed the thermocline ridge, where the thermocline was typically shallowest (Fig. 6). The dolphins spent about equal time along the ridge, where the thermocline depths were $<30 \mathrm{~m}$ and along the sharply contoured slope of the ridge, where the thermocline depths dropped from $30 \mathrm{~m}$ down to $60 \mathrm{~m}$ (Fig. 6, 7). In 1992, too few thermographic data were collected to produce a contour map of the thermocline structure in the study area, but the thermoclines measured were typically shallow (approximately $20 \mathrm{~m}$ ), and the thermal ridge produced between the westward-flowing North Equatorial Current and the eastward-flowing North Equatorial Countercurrent was within the study area (Ballance et al. 2006, Fiedler and Talley 2006). Thermal ridges are thought to concentrate aggregations of vertically migrating organisms (Fiedler et al. 1998, Ballance et al. 2006). 


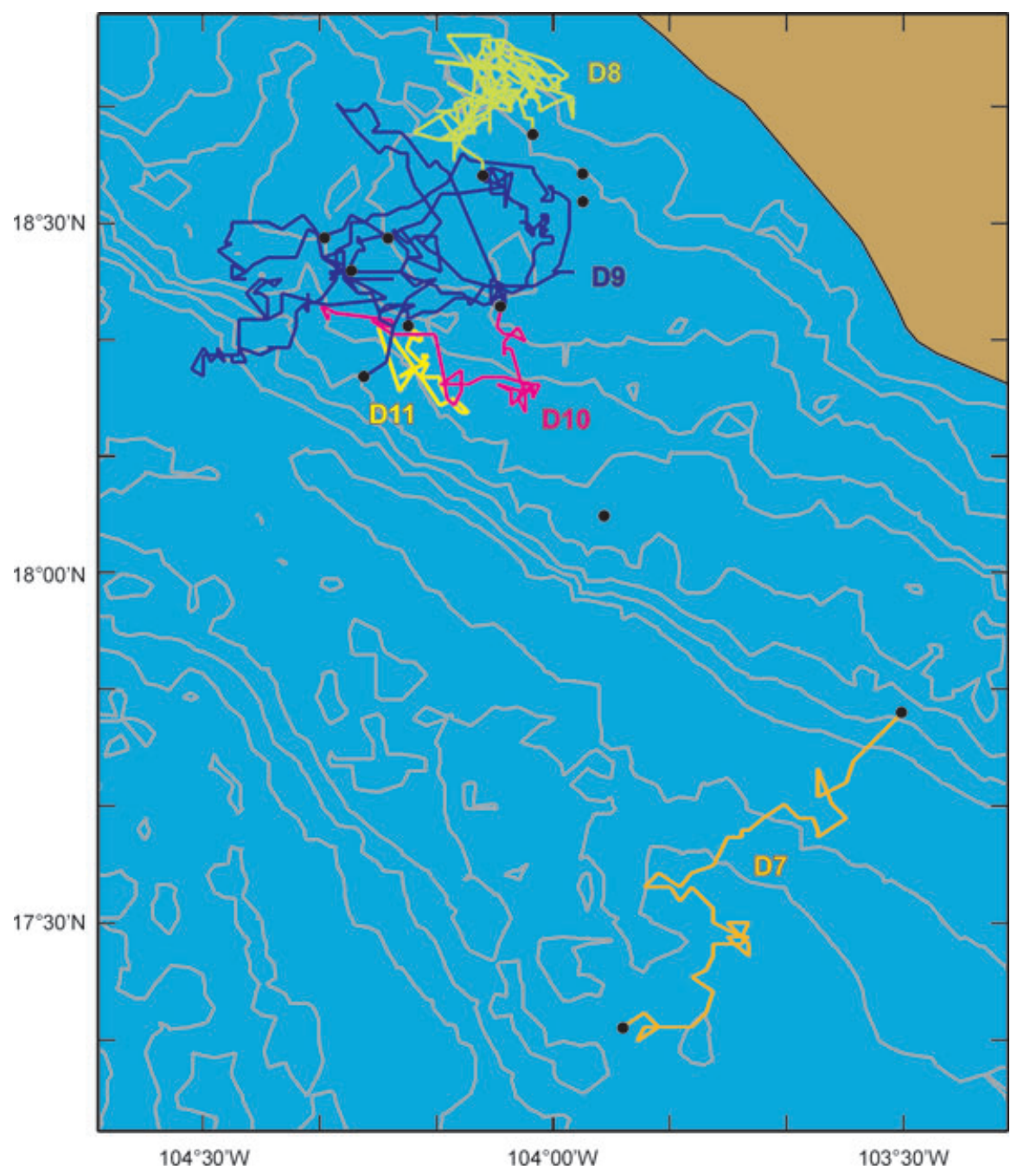

Figure 5. Movements of five dolphins tracked during 1993 plotted over 500-m bathymetry contours. Circles represent locations of sets on dolphin herds. The depth of the thermocline ranged from $25 \mathrm{~m}$ to $56 \mathrm{~m}$.

Longer term resightings of two visually tagged spotted dolphins were reported by Inter-American Tropical Tuna Commission (IATTC) observers aboard tuna vessels. Both dolphins were resighted at approximately the same time of year as they were tagged originally. One dolphin (D48, a female with a mottled color pattern) was resighted twice $11 \mathrm{mo}$ after it was initially tagged, about 275 and $300 \mathrm{~km} \mathrm{SE}$ of the tagging location. The second dolphin (D136, a mottled-phase animal of unknown sex) was resighted $35 \mathrm{mo}$ after it was initially tagged, about $350 \mathrm{~km}$ SE of the tagging location. 


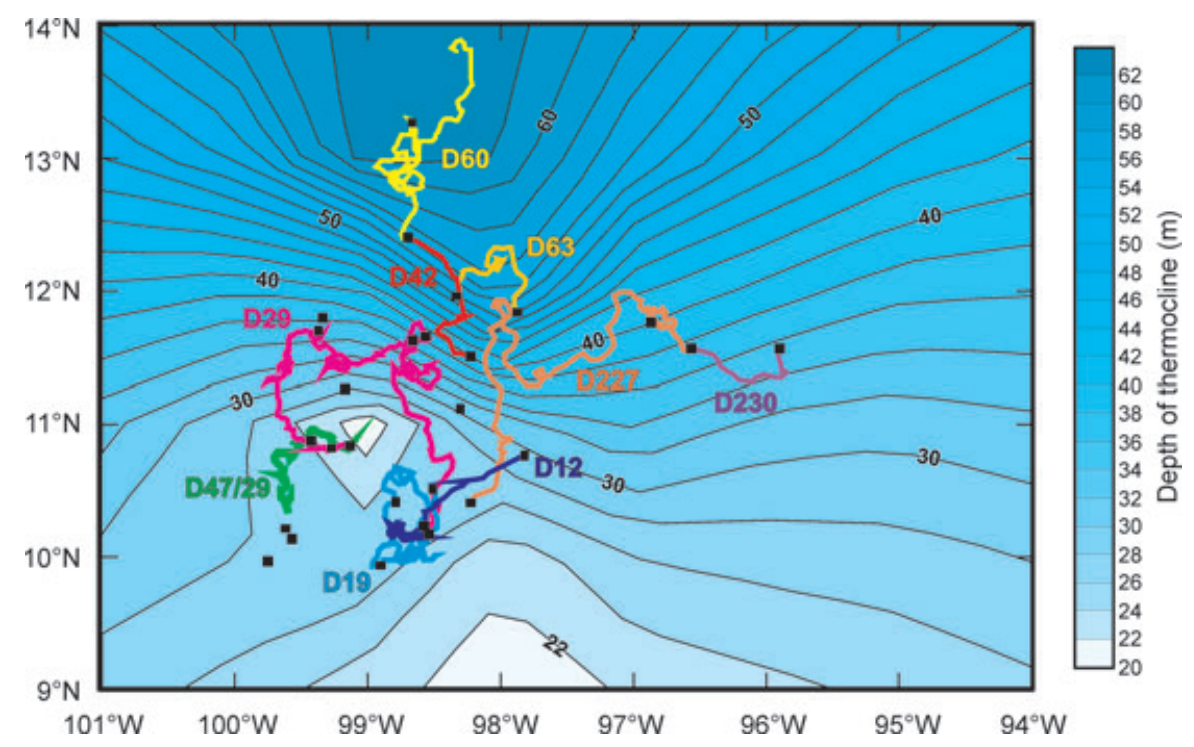

Figure 6. Movements of nine dolphins tracked during 2001. Each dolphin is color coded. Square symbols indicate the locations of sets on dolphin herds. Color scale indicates the depth of the thermocline in meters; 2-m contours show "ridging" of the thermocline. The depth of the thermocline ranged from $16 \mathrm{~m}$ to $76 \mathrm{~m}$.

\section{Herd Dynamics}

The release of several tagged dolphins from the same set provided an opportunity to study herd stability. Associations were surprisingly ephemeral. Of the nine radiotagged spotted dolphins released with focal dolphins, only one (11.1\%) was still in association with the focal dolphin the next day; the rest were beyond the 6-km range of the low-power bullet tags. Of the 82 tagged dolphins (noncalves with either visual, satellite, or radio tags) released with the 9 focal radio-tagged dolphins, only $12(14.6 \%)$ were still observed in association with the focal dolphin the next day.

\section{Diving Patterns}

Tracking the dolphins also provided an opportunity to recover the TDRs with their stored histories of the dolphins' diving behavior. We recaptured 12 of the 16 dolphins that carried TDRs after they had been at liberty for 1-6 d, and nine of the recovered TDRs provided useful dive histories. Over $477 \mathrm{~h}$ of diving data were collected, encompassing 8,694 dives $\geq 5 \mathrm{~m}$ in depth. The average dive depth was $14.4 \mathrm{~m}$ and the deepest dive depth was $203 \mathrm{~m}$.

Dive durations were collected in two different ways that produced two different measures. We manually recorded the intervals between radio signals that were received when the dolphins surfaced during the sampling period $(15 \mathrm{~min} / \mathrm{h})$, while the TDR data analyses considered only dives $\geq 5 \mathrm{~m}$. The manual method measures the amount of time spent below the surface (as would be useful in calculating respiration rates), while the TDR method measures only true dives, ignoring time spent just below the surface. However, the duration of some dives collected by the TDRs may 


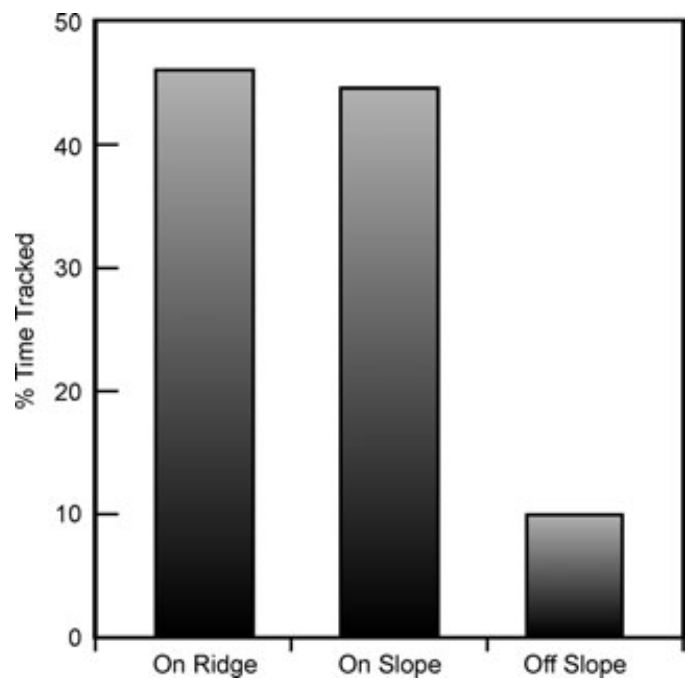

Figure 7. Histogram showing the percentage of time that tracked dolphins spent in relationship to the thermocline ridge (see Fig. 6). The "On ridge" category included thermocline depths $\leq 30 \mathrm{~m}$, the "On slope" category included the steeply contoured thermocline depths between 30 and $60 \mathrm{~m}$, and the "Off slope" category included thermocline depths $\geq 60 \mathrm{~m}$.

be overestimated, particularly in 1992, when the relatively low sampling rate (every $10 \mathrm{~s}$ ) and relatively low resolution $(2 \mathrm{~m}$ ) could mask some surfacings (see Wilson et al. 1995). Although the dive durations from the TDR data may be overestimated, they were used to examine day-night differences in diving behavior (Table 2); however, we excluded the maximum dive durations from 1992. The manually recorded surfacing times from 16 dolphins (based on 26,016 dives) yielded an average dive duration of $0.40 \mathrm{~min}$, with the longest dive being $5.3 \mathrm{~min}$, while the average TDR duration of dives $\geq 5 \mathrm{~m}$ from 9 dolphins (8,694 dives) was $1.52 \mathrm{~min}$, with the longest dive being $5.4 \mathrm{~min}$. These maximum dive durations are consistent with those recorded for other cetaceans of similar mass (Noren and Williams 2000).

The nine TDR dolphins displayed day-night differences in diving patterns (Fig. 811, Table 2). During the daytime, the spotted dolphins typically dove to a depth of 5-20 $\mathrm{m}$ and swam at those depths before returning to the surface (Fig. 9, 11). Virtually all of the daytime dives were above the thermocline (Fig. 8). The depth of the thermocline was $23-33 \mathrm{~m}$ in 1992, 25-56 $\mathrm{m}$ in 1993, and $16-76 \mathrm{~m}$ in 2001. Daytime dives were $\mathrm{U}$-shaped (the dives recorded in 1992 appeared more rectangular than those in later years because the depths were only recorded every $10 \mathrm{~s}$ ). Little change in depth (1-2 m) occurred at the bottom of these dives (Fig. 11). Because one might expect rapid changes in depth because of predators chasing prey in a three-dimensional environment (Bengtson and Stewart 1992, Testa 1992), it appears that these dives were most likely associated with traveling, rather than feeding.

At dusk, all nine dolphins typically began diving to greater depths, apparently to forage on vertically migrating prey organisms. The deeper nighttime dives were typically preceded by a series of 2-10 sequentially shallower dives (Fig. 8, 10). In 2001, echosounder data showed that these dives coincided with the ascent of organisms associated with the DSL (Fig. 10). The dusk diving bout lagged behind 
Table 2. Daytime (0600-1800) and nighttime (1800-0600) dive characteristics for pantropical spotted dolphins.

\begin{tabular}{lccr}
\hline \hline & Daytime dives & Nighttime dives & $P$ \\
\hline Mean dive duration (min): manual & $0.42(0.64)$ & $0.38(0.50)$ & $<0.01$ \\
Maximum dive duration (min): manual & 5.3 & 4.9 & \\
Mean dive duration (min): TDR & $1.26(0.89)$ & $1.68(1.02)$ & $<0.01$ \\
Maximum dive duration (min): TDR & 4.3 & 5.4 & \\
Mean dive depth (m) & $22.1(15.71)$ & $24.0(27.10)$ & $<0.01$ \\
Maximum dive depth (m) & 121 & 203 & \\
Mean interdive interval (min) & $1.14(5.08)$ & $0.83(1.81)$ & $<0.01$ \\
Mean surface time (min) & $0.99(4.89)$ & $0.79(1.78)$ & $<0.01$ \\
Mean bottom time (min) & $0.56(0.52)$ & $0.75(0.69)$ & $<0.01$ \\
Ratio: Bottom time/duration & $0.40(0.18)$ & $0.38(0.24)$ & 0.01 \\
Mean descent rate (m/s) & $0.58(0.34)$ & $0.93(0.54)$ & $<0.01$ \\
Mean ascent rate (m/s) & $-0.42(0.24)$ & $-0.74(0.41)$ & $<0.01$ \\
\hline
\end{tabular}

The means are unweighted and calculated using all data for each dolphin; the maximum dive depth and duration, however, are the maximum for all the individuals combined. Standard deviations are in parentheses. The manually recorded dive durations were calculated from 26,016 dives (9,733 day; 16,283 night) by 12 dolphins; the other parameters were data collected by the TDRs and calculated from 8,694 dives (3,273 day; 5,421 night) by 9 dolphins.

the DSL ascent by 10-25 min, as might be expected if prey such as squids (which do not show up in the echosounder traces) were following the DSL toward the surface. The dives extended to the bottom of the DSL and below, again the depth one might expect to find squids. The 16 bouts during 20 evenings began $7-35$ min after sunset $(\bar{x}=26 \mathrm{~min})$ and lasted $5-35 \mathrm{~min}(\bar{x}=22 \mathrm{~min})$.

Deep dives below the thermocline continued throughout the night (Fig. 8), although the pattern varied from one night to the next. During some nights, deepdiving bouts were apparent, while on others, dives to a consistent depth were made throughout the night. The 2001 echosounder data showed that the DSL organisms were near the surface, and TDRs showed that the dolphins were diving to the bottom of this thick concentration of DSL organisms at the surface (Fig. 10). The nighttime dives were also U-shaped, but with more rapid changes in depth while at the bottom of the dive ("wiggles"), suggesting the pursuit of prey (Fig. 11). The nighttime dives were significantly longer and deeper, with greater time spent near the bottom of the dives, than daytime dives. The ascent and descent rates of the nighttime dives were significantly greater than daytime dives (Table 2).

The predawn dive bouts were a mirror image of the dusk dive bouts (Fig. 8). The 16 predawn bouts observed during 20 mornings consisted of a series of two to seven sequentially deeper dives. The bouts began 36-69 min before sunrise $(\bar{x}=$ $50 \mathrm{~min})$ and lasted approximately $4-32 \mathrm{~min}(\bar{x}=17 \mathrm{~min})$. The depths of the dives ranged from 25 to $203 \mathrm{~m}$ (average depth of deepest dive in the bout $=92 \mathrm{~m}$ ). The 2001 echosounder data allowed us to compare the timing of these predawn diving bouts with the descent of organisms associated with the DSL (Fig. 10). The predawn diving bout preceded the DSL descent by 5-20 min, as the dolphins were tracking descending prey, such as jumbo flying squids (Dosidicus gigas) that begin their descent earlier than the DSL, about 50 min before sunrise (Yatsu et al. 1999). 


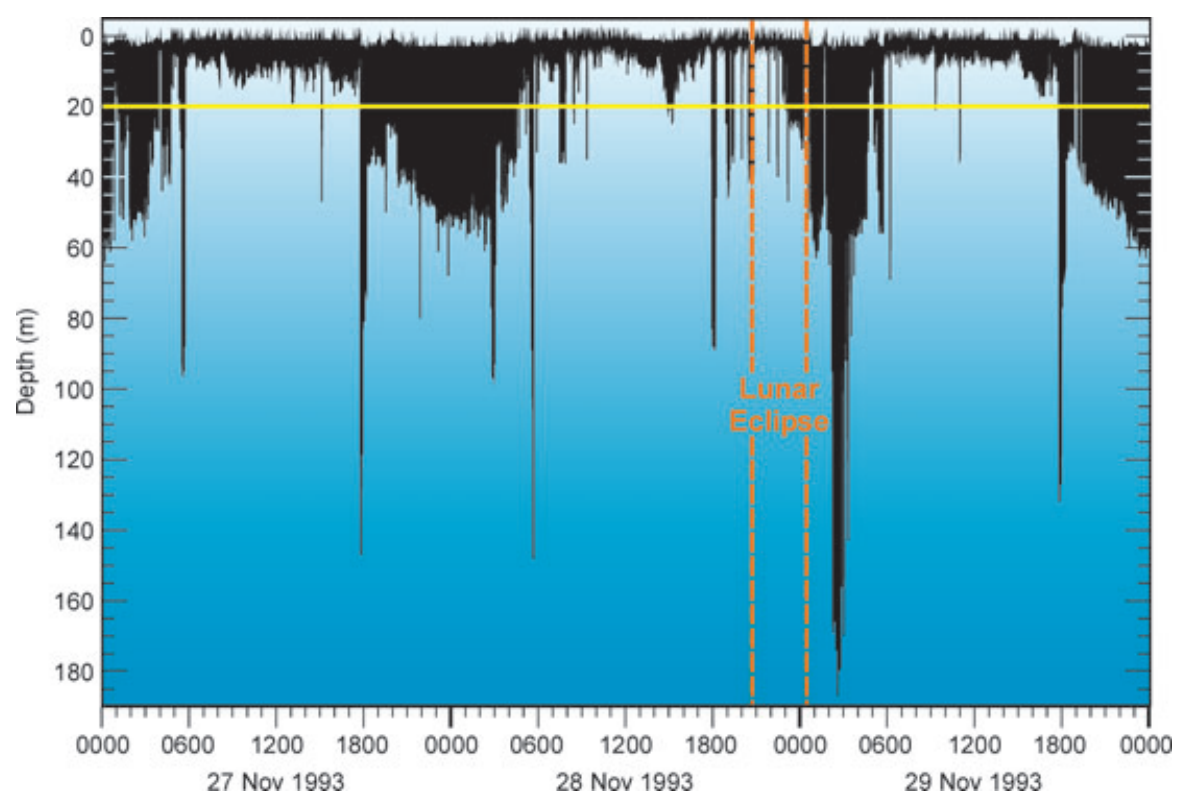

Figure 8. Diving history of D9 during 27-29 November 1993. Depth of the thermocline $(22 \mathrm{~m})$ is indicated by the yellow line. The duration of the lunar eclipse is indicated for the night of 28-29 November 1993; the moon was fully eclipsed at 2302. Note that the depth trace did not always return to zero when the dolphin surfaced while making rapid, sequential dives.

The deepest dives observed were about $200 \mathrm{~m}$, suggesting that prey below this depth was unavailable. Most of the deepest dives were observed during the dusk and dawn diving bouts. The dolphins appear to first encounter upwardly migrating prey at depths of $61-200 \mathrm{~m}(\bar{x}=107 \mathrm{~m}, n=16)$, and stop pursuing descending prey prior to dawn at depths of 38-203 $\mathrm{m}(\bar{x}=92 \mathrm{~m})$. The dawn and dusk dives differed significantly $(P<0.01)$ from the nighttime dives using the mixed-effects model. They were on average deeper, with faster ascent and descent rates, and less bottom time than the nighttime dives recorded between the dawn and dusk periods.

The feeding durations (measured from the beginning of the dusk dive bout to end of the predawn bout) ranged from 10.6 to $11.9 \mathrm{~h}(n=7$ dolphins, 15 nighttime observations). There was a significant difference among animals $(P=0.04$, KruskalWallis one-way ANOVA test). This difference is likely due to the effect of photoperiod on the DSL, the effect of prey associated with the DSL on dolphin foraging times, and the effects of seasons and latitudes of the three study areas on the number of hours of darkness. The feeding durations observed during August-September 2001 ( $\bar{x}=$ $10.8 \mathrm{~h}$ ) were shorter than those observed in November 1992 (11.3 h) and November 1993 ( $11.9 \mathrm{~h}$ ) when the nights were longer. The feeding durations during November 1992 were shorter because the study area was farther south $\left(9^{\circ}-11^{\circ}\right.$ latitude) than the 1993 study area $\left(17^{\circ}-18^{\circ}\right.$ latitude) where the fall nights were longer.

During the track of D9, we also had the opportunity to observe the effects of a full lunar eclipse on dolphin diving behavior (Fig. 8). Given the influence of light levels on the depth of the DSL, the eclipse provided a natural experiment to observe 


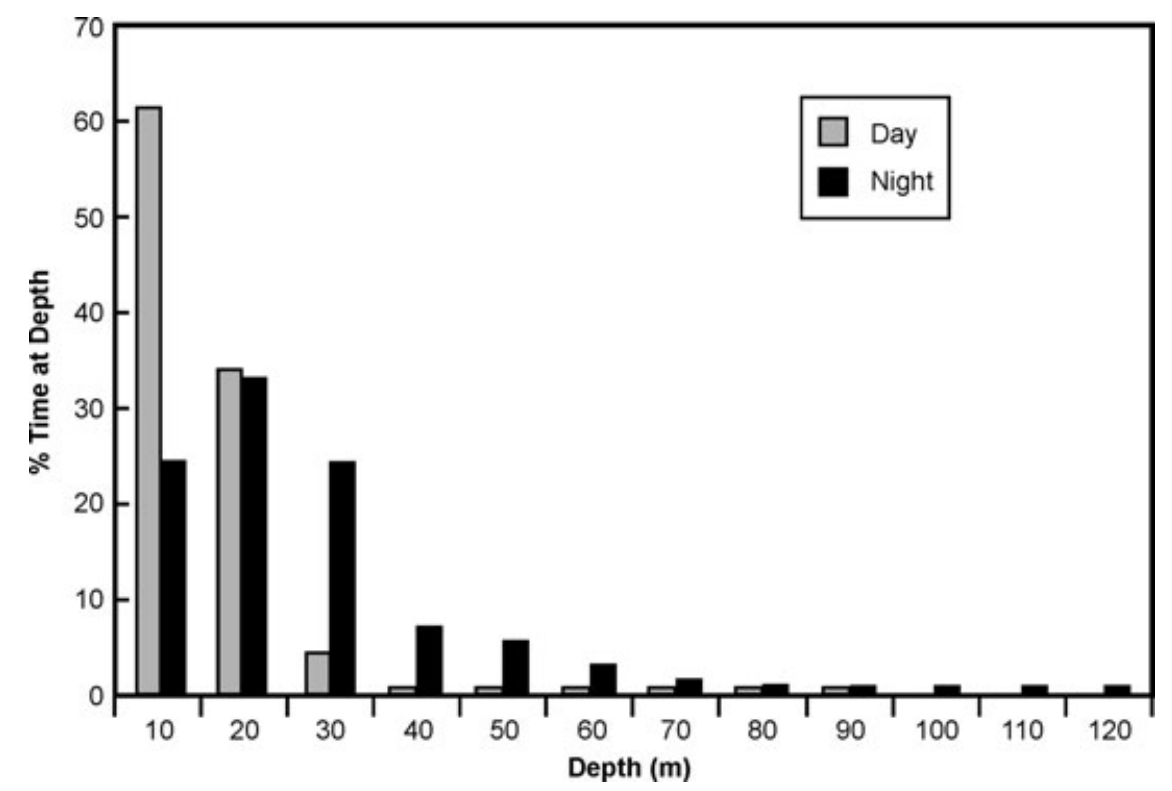

Figure 9. Comparison of daytime and nighttime dive depth. To be considered a dive in this analysis, the minimum depth was defined as $5 \mathrm{~m}$. Dives to $120 \mathrm{~m}$ and deeper did occur, but constituted $<0.1 \%$ of the dives and are not shown in the histogram.

how light levels influence prey availability and spotted dolphin diving behavior. Prior to the onset of the eclipse on 28 November 1993 at 2142, the moon was full and unobscured by clouds. D9 made only sporadic deep dives to about $40 \mathrm{~m}$, suggesting that prey organisms may have been too deep to capture because of the relative brightness of the full moon prior to the eclipse (Tarling et al. 1999). After the moon was fully eclipsed at 2302, however, D9 began to dive more regularly to 30-60 m, suggesting that prey species had moved closer to the surface. D9 continued to dive throughout the remainder of the night, during which the moon was usually veiled or obscured by clouds. An hour-long bout of deep dives $(140-187 \mathrm{~m})$ that occurred between 0215 and 0315 coincided with a period of increased moonlight when the clouds gradually parted.

\section{DISCUSSION}

\section{Movements}

Two movement patterns were displayed by the tracked dolphins. A pelagic pattern was displayed by the dolphins in 1992 and 2001, and by D7 in 1993; their tracks often contained segments during which the dolphins traveled in roughly the same direction for long periods of time (Fig. 4-6). Previous radio-tracking studies of spotted dolphins in the ETP (Leatherwood and Ljungblad 1979, Perrin et al. 1979) showed a similar pattern. A different pattern was displayed by dolphins (D8-D11) tracked in 1993 over the continental slope; these dolphins frequently changed direction as if they were patrolling the area (Fig. 5). Their tracks were similar to those 

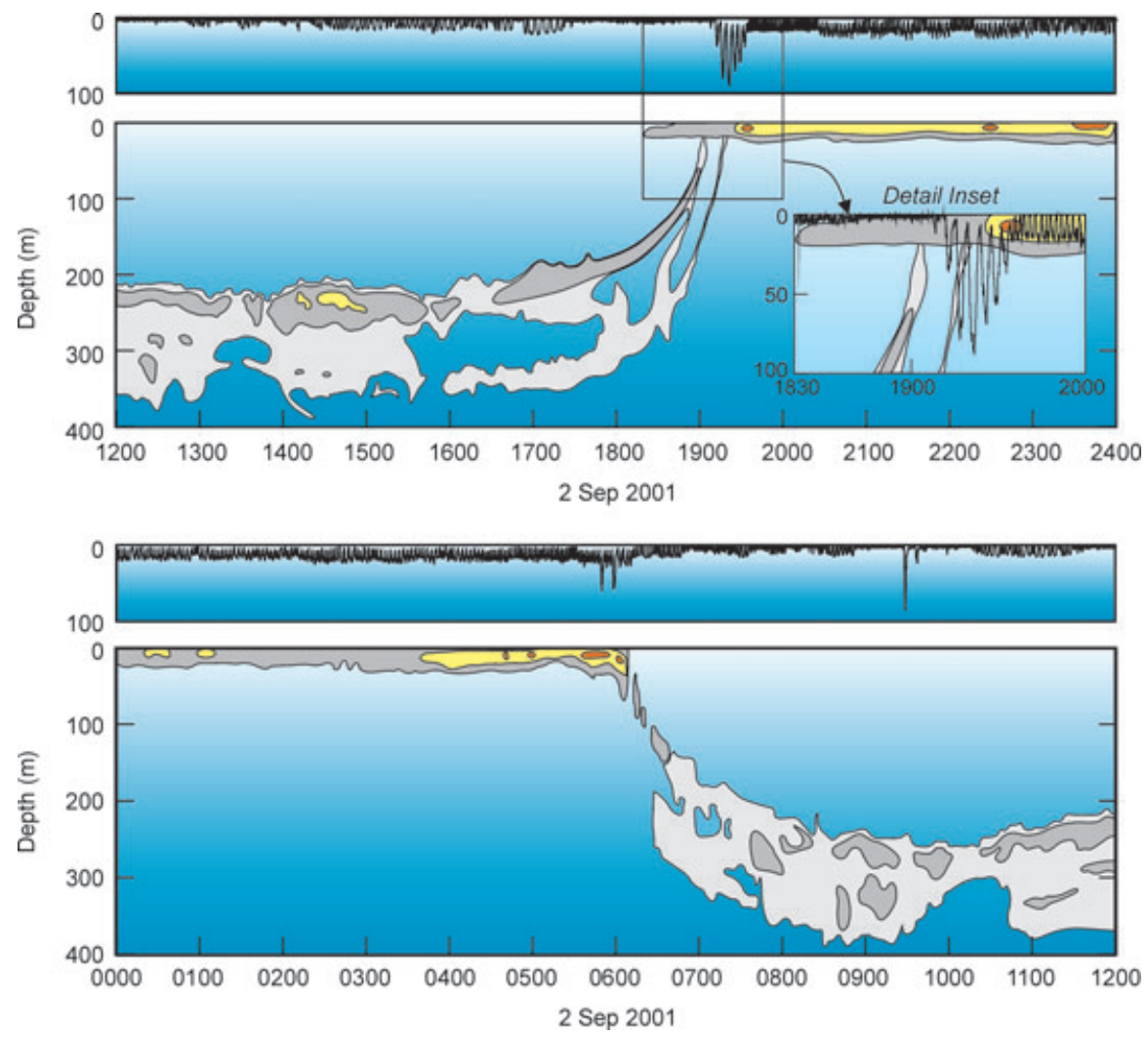

Figure 10. Time-depth plot of D29 dives and simultaneous EK500-echosounder record of the deep scattering layer (DSL). The upper plots (1200-2400; 2 September 2001) show the DSL rising around sunset $(1848 \mathrm{~h})$ and the dolphin's transition from daytime dives to dusk deep-diving bout to nighttime dives. The inset shows the dusk diving bout overlaid on the DSL in greater detail. The lower plots (0000-1200; 2 September 2001) show the DSL migrating deeper prior to dawn (at 0629) and the dolphin's transition from nighttime dives to dawn deep-diving bout to daytime dives. The densities of DSL organisms are color coded: light gray for the lowest densities, dark gray for medium densities, yellow for high densities, and orange for the most dense patches. Note that there is a small geographic difference in the two records; the echosounder data were from directly under the McArthur, while the dolphins were typically $\geq 4 \mathrm{~km}$ away.

of spotted dolphins along the continental shelf and slope off Hawaii and Atlantic spotted dolphins (S. frontalis) along the continental shelf off Texas (Scott and Wussow 1983, Davis et al. 1996, Baird et al. 2001).

The dolphins' movements followed oceanographic features associated with higher productivity. The thermocline ridges in the ETP have been correlated with increased biological production and have been shown to be prime spotted dolphin habitat (Au and Perryman 1985, Reilly 1990). The continental slope, under certain wind conditions, can produce intense upwelling that also increases productivity. 

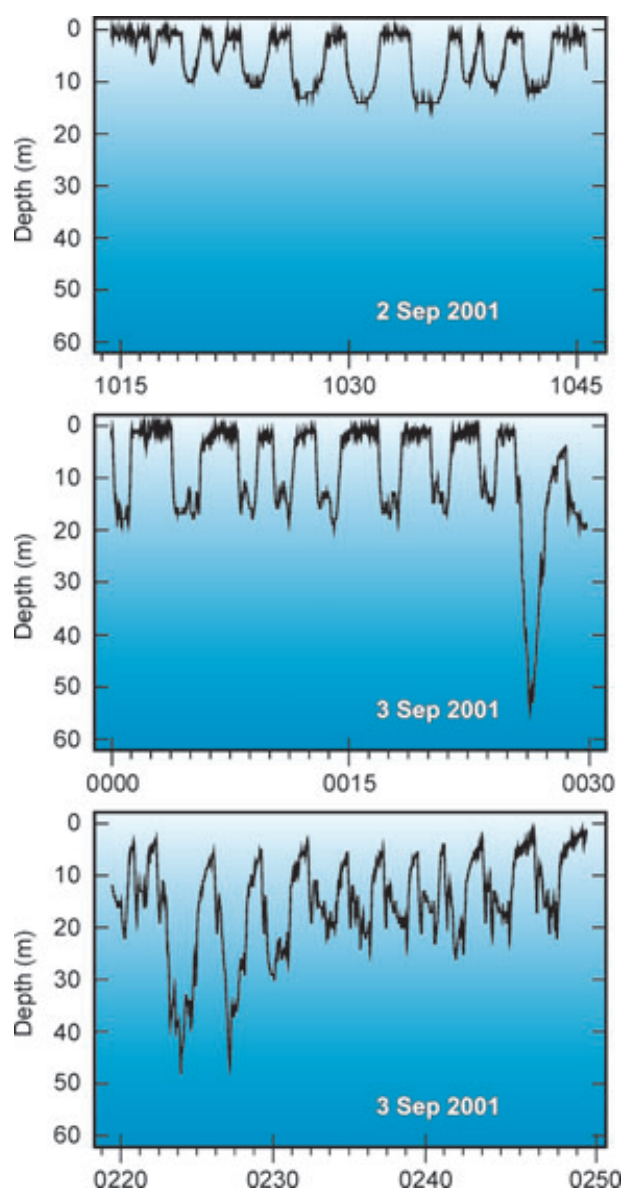

Figure 11. Daytime and nighttime diving patterns of dolphin D29: 30-min samples of the daytime pattern (top: 1015-1045, 2 September 2001), and two examples of nighttime dives (middle: 0000-0030, 3 September 2001; bottom: 0220-0250, 3 September 2001). Note that the depth trace did not always return to zero when the dolphin surfaced while making rapid, sequential dives.

\section{Herd Dynamics}

Herds of spotted, spinner, and common dolphins increase in size throughout the day, and then fragment at night when they feed (Scott and Cattanach 1998). The associations of multiple spotted dolphins tracked simultaneously in this study confirmed the dynamic nature of pelagic dolphin herds. The herds we followed were ephemeral entities, with less than $15 \%$ of the dolphins that were tagged together being found together in the same herd the following day. Tagged dolphins separated and rejoined over the course of several days and herds fluctuated in size and membership throughout the day (see also Perrin et al. 1979, Scott and Cattanach 1998). 
Fission-fusion societies have been described for coastal dolphins that form small herds that change composition on an hourly or daily basis (Connor et al. 2000), but pelagic spotted dolphins appear to have fission-fusion societies at a grand scale. While coastal bottlenose dolphins typically occur in herds of 2-15 and spotted dolphins around islands typically occur in herds of 10-150 (Baird et al. 2001, Wells and Scott 1999), pelagic spotted dolphins typically occur in herds of hundreds or thousands of dolphins. How do spotted dolphins maintain social relationships when they occur in such large and ephemeral herds? We suggest that there are small subunits within these herds that are stable over time. We observed several small subgroups $(\leq 12$ animals) within the herds that were more stable from one day to the next, and aerial photographs show that large herds of pelagic dolphins are not homogeneous, but rather are an amalgamation of small subgroups traveling in echelon formation (Scott and Perryman 1991).

\section{Diving Behavior}

From the TDR diving histories, the dolphins' feeding times and depths and their preferred swimming depths can be inferred and interpreted relative to the depth of the thermocline and the vertical movements of the DSL. The diving patterns we observed were similar to those of spotted dolphins off Hawaii (Baird et al. 2001). In both studies, the spotted dolphins traveled relatively deep during the daytime and tracked the rise and fall of the DSL near dusk and dawn. Also, the nighttime dive depths and durations and the ascent and descent rates were all greater than those during the daytime, while the time spent near the surface was less. The diving pattern was quite different from that of a stranded, rehabilitated, and released Atlantic spotted dolphin however (Davis et al. 1996). This dolphin's dives were limited in depth because it remained over the continental shelf in 20-60 m of water and no day-night pattern in the dives was observed.

The depth and shape of the daytime dives were consistent from dive to dive, from day to day, and from individual to individual. The typical depths of these dives $(15-20 \mathrm{~m})$ were above the thermocline, but surprisingly deep. The daytime dives were deeper than necessary to avoid the drag that occurs within $\sim 1 \mathrm{~m}$ of the water's surface (Au and Weihs 1980). These dives were presumed not to be feeding dives because they lacked the rapid changes in depth associated with pursuit of prey (Bengtson and Stewart 1992, Testa 1992). In the absence of obvious hydrodynamic or feeding advantages for traveling at these depths, one can conjecture that it allows the dolphins to visually or acoustically scan the waters of the mixed layer more readily. Dolphins swimming at depth could avoid interference to their vision or echolocation caused by surface glare, waves, and bubbles. Avoiding this interference would likely improve their ability to see silhouettes of potential predators above them and to detect predators acoustically at deeper depths.

The dolphins dove deeper at night, apparently to feed on vertically migrating organisms associated with the DSL, but the nighttime diving patterns varied a great deal. The DSL is predominantly made up of myctophid fishes that come to the surface to prey on copepods, euphausids, and sergistids that rise to feed on phytoplankton near the surface (e.g., Dietz 1962). They, in turn, are preyed upon by vertically migrating mesopelagic squids that follow the DSL to the surface, and by epipelagic fishes and squids. With the exception of the crustaceans, all of these are preyed upon by spotted dolphins. The spotted dolphins often dove beneath the DSL, a pattern 
also seen in common dolphins (Evans 1971), to depths where mesopelagic squids are often found.

The depth of the DSL is strongly influenced by light; it is deepest when the sky is bright during daytime and nearest the surface during moonless or cloudy nights. Changing light levels, through the influence on the depth of the DSL, probably helps create the variability of the nighttime dive patterns. The effect of light on dolphin diving was particularly evident during the lunar eclipse on 28 November 1993. Dolphin D8's diving behavior was more erratic on that night than any other night as the light levels changed dramatically as the full moon went from shining brightly, to eclipsed, to full brightness again, and then to mostly obscured by clouds.

The DSL would be expected to be shallower during cloudy days than on bright, sunny days (Blaxter 1975). Radio tracks of a pygmy sperm whale (Kogia breviceps) and common dolphins continued to make apparent deep foraging dives during the day when the sky was overcast (Evans 1974, Scott et al. 2001). For the spotted dolphins tracked in this study, however, deep, foraging dives were not observed during overcast days, suggesting that their prey was still too deep to capture efficiently or that the dolphins were satiated after nighttime foraging.

The diving behavior of spotted dolphins is consistent with food-habits and radiotracking studies that indicate they are primarily nighttime or crepuscular feeders that prey, at least partially, on vertically migrating fish and squids (Shomura and Hida 1965, Fitch and Brownell 1968, Perrin et al. 1973, Leatherwood and Ljungblad 1979, Scott and Wussow 1983, Robertson and Chivers 1997, Scott and Cattanach 1998, Galván-Magaña 1999, Baird et al. 2001, Wang et al. 2003). The deepest dives occurred typically at dusk and before dawn, in conjunction with the ascent and descent of the DSL. Fiedler et al. (1998) correlated dolphin abundance in the ETP with the density of organisms associated with the DSL, and the influence of the vertical migration of the DSL on dolphin behavior has also been observed in Hawaiian spotted and spinner dolphins (Baird et al. 2001, Benoit-Bird and Au 2003), common dolphins (Evans 1974), and dusky dolphins (Lagenorhynchus obscurus; Benoit-Bird et al. 2004).

Characteristics of the dusk and dawn dives, relative to other nighttime dives, show that dolphins increase surface-to-depth swimming speeds in order to dive deep enough to reach the vertically migrating DSL organisms, at the expense of limiting the time at the bottom of their dives. Yet dive duration is no longer than other nighttime dives, suggesting that dive duration may limit the dive behavior of these dolphins and that to dive deep they must strike a balance between the speed of their ascent and descent with the amount of time spent at the bottom of their dive.

\section{Summary}

Tracking data from 20 spotted dolphins suggested that their movements are associated with oceanographic features, such as thermocline ridges and the continental slope, which are indicative of relatively high biological productivity. Dolphins nearer to the coast patrolled over the continental slope, while more-offshore dolphins traveled along "ridges" in the thermocline structure. Pelagic dolphin herds were confirmed to be dynamic, changing in size, membership, and species composition from one day to the next. Dive data from nine spotted dolphins revealed distinct day-night patterns. During the daytime, the dolphins mainly traveled at depths of $15-20 \mathrm{~m}$. During the nighttime, the dolphins traveled more slowly but dove deeper and longer, with more rapid ascents and descents than during daylight hours. The 
dive data indicate that spotted dolphins are predominantly nocturnal and crepuscular feeders that track the vertical movements of organisms associated with the DSL at night.

\section{ACKNOWLEDGMENTS}

It became evident early in this study that its success depended greatly on the cooperation, experience, and skill of the captains and crews of the tuna seiners and the McArthur. The skippers of the purse seiners showed much patience, and their experience allowed us to capture the dolphins as safely and effectively as possible. The skill and persistence of these skippers and their crews were particularly valuable in the recapturing of the dolphins tagged with TDRs. CDR Dave Peterson, CDR Michelle Bullock, CDR Craig Bailey, and the crew of the McArthur provided support, advice, and encouragement to safely conduct our operations. The crew integrated themselves into every facet of the research: tagging and tracking dolphins, logistical support, and collecting environmental data. The purse seiners were chartered by the NMFS $(1992,2001)$, the IATTC $(1993,2001)$, and the Programa Nacional para el Aprovechamiento del Atún y Protección de los Delfines of Mexico (1993). Funding was provided by the NMFS, the IATTC, and Dolphin Biology Research Institute. We thank the small army of people from the IATTC, NMFS, and the NOAA Corps who supported the project logistically. We thank the biologists who accompanied us in the field: Gabriel Aldana, Eric Archer, Wes Armstrong, Jenny Asch, David Au, Lisa Ballance, Ernesto Beyliss Cortez, Dave Bratten, Kerri Danil, Karin Forney, Marco García, Roger Geertsema, Jim Gilpatrick, Kim Holland, Rick Lindsey, Bill McLellan, Erin Meagher, Greg O'Corry-Crowe, Bob Olson, Bob Pitman, Jesús Ramírez, Howard Rhinehart, David St. Aubin, Forrest Townsend, Andrew Westgate, Bradley Wetherbee, Suzanne Yin, and Ernesto Vásquez. Jessica Redfern and Liz Zele processed and provided the echosounder data, David Demer and Roy Allen who assisted in the production of the manuscript's graphics, and Cleridy Lennert-Cody who provided statistical help. We also thank several reviewers whose suggestions helped improve the manuscript: Jay Barlow, Bill Bayliff, Liz Edwards, Janet Mann, Bob Olson, Bill Perrin, Steve Reilly, Barb Taylor, and two anonymous reviewers.

\section{LITERATURE Cited}

Au, D. W. K, And W. L. Perryman. 1985. Dolphin habitats in the eastern tropical Pacific. Fishery Bulletin 83:623-643.

Au, D. W., AND R. L. Pitman. 1988. Seabird relationships with tropical tunas and dolphins. Pages 174-121 in J. Berger, ed. Seabirds and other marine vertebrates: Competition, predation and other interactions. Columbia University Press, New York.

Au, D., AND D. Weins. 1980. At high speeds dolphins save energy by leaping. Nature 284:548-550.

BallanCe, L. T., R. L. Pitman AND P. C. FiedleR. 2006. Oceanographic influences on seabirds and cetaceans of the eastern Pacific: A review. Progress in Oceanography 69:360-390.

Baird, R. W., A. D. Ligon, S. K. Hooker and A. M. Gorgone. 2001. Subsurface and nighttime behaviour of pantropical spotted dolphins in Hawaii. Canadian Journal of Zoology 79:988-996.

Bengtson, J. L., AND B. S. Stewart. 1992. Diving and haulout behavior of crabeater seals in the Weddell Sea, Antarctica, during March 1986. Polar Biology 12:635-644.

BenOIT-BIRD, K. J., AND W. W. L. Au. 2003. Prey dynamics affect foraging by a pelagic predator (Stenella longirostris) over a range of spatial and temporal scales. Behavioral Ecology and Sociobiology 53:364-373.

BeNOIT-BIRD, K. J., B. WÜRSIG AND C. J. MCFAdDEN. 2004. Dusky dolphin (Lagenorhynchus obscurus) foraging in two different habitats: Active acoustic detection of dolphins and their prey. Marine Mammal Science 20:215-231. 
Blaxter, J. H. S. 1975. The role of light in the vertical migration of fish-a review. Pages 189-210 in G. C. Evans, R. Bainbridge and O. Rackham, eds. Light as an ecological factor: II. Blackwell, Oxford, UK.

Bulgakov, S. N., N. P. Bulgakov, E. N. Mikhailova and N. B. Shapiro. 2005. Generation of upwelling near the Pacific coast of Mexico. Physical Oceanography 15:27-36.

Butler, R. W., And J. G. Jennings. 1980. Radio tracking of dolphins in the eastern tropical Pacific using VHF and HF equipment. Pages 757-759 in C. Amlaner and D. MacDonald, eds. A handbook on biotelemetry and radio tracking. Pergamon, New York.

CoE, J., AND G. SousA. 1972. Removing porpoise from a tuna purse seine. Marine Fisheries Review 34(11-12):15-19.

Connor, R. C., R. S. Wells, J. Mann and A. J. Read. 2000. The bottlenose dolphin: Social relationships in a fission-fusion society. Pages 91-126 in J. Mann, R. Connor, P. Tyack and H. Whitehead, eds. Cetacean societies: Field studies of dolphins and whales. Chicago University Press, Chicago, IL.

Davis, R. W., G. A. J. Worthy, B. Würsig AND S. K. LYNN. 1996. Diving behavior and at-sea movements of an Atlantic spotted dolphin in the Gulf of Mexico. Marine Mammal Science 12:569-581.

DiETZ, R.S. 1962. The sea's deep scattering layers. Scientific American 207(2):44-50.

Dizon, A. E., W. F. Perrin AND P. A. AkIN. 1994. Stocks of dolphins (Stenella spp. and Delphinus delphis) in the eastern tropical Pacific: A phylogeographic classification. National Oceanographic and Atmospheric Administration Technical Report NMFS 119. 20 pp.

Evans, W. E. 1971. Orientation behavior of delphinids: Radio telemetric studies. Annals of the New York Academy of Science 188:142-160.

Evans, W. E. 1974. Radio-telemetric studies of two species of small odontocete cetaceans. Pages 385-394 in W. Schevill, ed. The whale problem: A status report. Harvard University Press, Cambridge, MA.

Fiedler, P. C., J. BArlow, AND T. GerrodetTe. 1998. Dolphin prey abundance determined from acoustic backscatter data in eastern Pacific surveys. Fishery Bulletin, U.S. 96:237247.

Fiedler, P. C., AND L. D. TAlley. 2006. Hydrography of the eastern tropical Pacific: A review. Progress in Oceanography 69:143-180.

Fitch, J. E., AND R. L. BROWNELl. 1968. Fish otoliths in cetacean stomachs and their importance in interpreting feeding habits. Journal of the Fishery Research Board of Canada 25:2561-2574.

Galván-Magaña, F. 1999. Relaciones tróficas ínterespecíficas de la comunidad de depredadores epipelágicos del Océano Pacífico oriental. Ph.D. thesis, Centro de Investigación Científica y de Educación Superior de Ensenada, Ensenada, Baja California, Mexico. 212 pp.

InTER-American Tropical Tuna Commission (IATTC). 2004. 2003 annual report. 98 pp. [In English and Spanish]

Kessler, W.S. 1990. Observations of long Rossby waves in the northern tropical Pacific. Journal of Geophysical Research-Oceans 95:5183-5217.

LEATHERWOOD, S., AND W. E. Evans. 1979. Some recent uses and potentials of radiotelemetry in field studies of cetaceans. Pages 1-31 in H. Winn and B. Olla, eds. Behavior of marine animals. Volume 3. Cetaceans. Plenum, New York.

LEATHERWOOD, S., AND D. K. LJUNGBLAD. 1979. Nighttime swimming and diving behavior of a radio-tagged spotted dolphin, Stenella attenuata. Cetology 34:1-6.

Noren, S.R., AND T. M. Williams. 2000. Body size and skeletal muscle myoglobin of cetaceans: Adaptations for maximizing dive duration. Comparative Biochemistry and Physiology, Part A 126:181-191.

Norris, K. S., AND T. P. DOHL. 1980. The structure and function of cetacean schools. Pages 211-261 in L. Herman, ed. Cetacean behavior: Mechanisms and functions. Wiley, New York. 
Perrin, W. F. 1969. Color pattern of the eastern Pacific spotted porpoise, Stenella graffmani Lönnberg (Cetacea, Delphinidae). Zoologica 54:135-142, pl. 1-7.

Perrin, W. F., R. R. WARner, C. H. Fiscus AND D. B. Holts. 1973. Stomach contents of porpoise, Stenella spp., and yellowfin tuna, Thunnus albacares, in mixed-species aggregations. Fishery Bulletin 71:1077-1092.

Perrin, W. F., D. B. Holts And W. E. Evans. 1979. Movements of pelagic dolphins (Stenella spp.) in the eastern tropical Pacific as indicated by results of tagging, with summary of tagging operations, 1969-1976. National Oceanographic and Atmospheric Administration Technical Report NMFS SSRF-737. 14 pp.

Perrin, W. F., M. D. Scott, G. Jay Walker and V. L. Cass. 1985. Review of geographical stocks of tropical dolphins (Stenella spp. and Delphinus delphis) in the eastern Pacific. National Oceanographic and Atmospheric Administration Technical Report NMFS 28. 28 pp.

Reilly, S. B. 1990. Seasonal changes in distribution and habitat differences among dolphins in the eastern tropical Pacific. Marine Ecology Progress Series 66:1-11.

Robertson, K. M., AND S. J. ChIVERS. 1997. Prey occurrence in pantropical spotted dolphins, Stenella attenuata, from the eastern tropical Pacific. Fishery Bulletin 95:334-348.

SCOTT, M. D., AND K. CATTANACH. 1998. Diel patterns in aggregations of pelagic dolphins and tunas in the eastern Pacific. Marine Mammal Science 14:401-428.

SCOTt, M. D., AND W. L. Perryman. 1991. Using aerial photogrammetry to study dolphin school structure. Pages 227-241 in K. Pryor and K. S. Norris, eds. Dolphin societies: Discoveries and puzzles. University of California Press, Los Angeles, CA.

ScotT, M. D., AND P. C. Wussow. 1983. Movements of a Hawaiian spotted dolphin. Pages 353-364 in D. Pincock, ed. Proceedings of the Fourth International Wildlife Biotelemetry Conference, Halifax, Nova Scotia, Canada. 364 pp.

Scott, M. D., R. S. Wells, A. B. Irvine And B. R. Mate. 1990. Tagging and marking studies on small cetaceans. Pages 489-514 in S. Leatherwood and R. Reeves, eds. The bottlenose dolphin. Academic Press, San Diego, CA.

Scott, M. D., A. A. Hohn, A. J. Westgate, J. R. Nicolas, B. R. Whitaker and W. B. CAMpBell. 2001. A note on the release and tracking of a rehabilitated pygmy sperm whale (Kogia breviceps). Journal of Cetacean Research and Management 3:8794.

SHOMURA, R. S., AND T. S. HidA. 1965. Stomach contents of a dolphin caught in Hawaiian waters. Journal of Mammalogy 46:500-501.

Tarling, G. A., F. Buchholz and J. B. L. Matthews. 1999. The effect of a lunar eclipse on the vertical migration behaviour of Meganyctiphanes norvegica (Crustacea: Euphausiacea) in the Ligurian Sea. Journal of Plankton Research 21:1475-1488.

Testa, W. [convener]. 1992. Analysis of data from time-depth recorders and satellite-linked time-depth recorders: Report of a technical workshop. Institute of Marine Science, University of Alaska, Fairbanks, AK. 29 pp.

Wang, M.-C., W. A. Walker, K.-T. Shao And L.-S. Chou. 2003. Feeding habits of the pantropical spotted dolphin, Stenella attenuata, off the eastern coast of Taiwan. Zoological Studies 42:368-378.

Wells, R. S., AND M. D. ScOTT. 1999. Bottlenose dolphin-Tursiops truncatus (Montagu, 1821). Pages 137-182 in S. H. Ridgway and R. Harrison, eds. Handbook of marine mammals. Volume 6. Academic Press, San Diego, CA.

Westgate, A. J., W. A. Mclellan, R. S. Wells, M. D. Scott, E. M. Meagher and D. A. PABST. 2007. A new device to remotely measure heat flux and skin temperature from free-swimming dolphins. Journal of Experimental Marine Biology and Ecology 346:45-59.

Wilson, R. P., K. Pütz, J. B. Charrassin And J. Lage. 1995. Artifacts arising from sampling interval in dive depth studies of marine endotherms. Polar Biology 15:575-581.

WYRTKI, K. 1966. Oceanography of the eastern equatorial Pacific Ocean. Oceanography and Marine Biology Annual Review 4:33-68. 
Yatsu, A., K. Yamanaka and C. Yamashiro. 1999. Tracking experiments of the jumbo flying squid, Dosidicus gigas, with an ultrasonic telemetry system in the eastern Pacific Ocean. Bulletin of the National Research Institute of Far Seas Fisheries 36:55-60.

Received: 25 May 2007

Accepted: 12 July 2008

\section{SUPPORTING INFORMATION}

Additional Supporting Information may be found in the online version of this article:

Table S1. Summary of sets and tagging and tracking operations during 1992. The bold-faced dolphin identification numbers indicate that the dolphin was the focal animal at that time. Dolphin identification numbers with an asterisk indicate that a calf was associated with the female. "Missed" indicates that an unsuccessful attempt to recapture the focal dolphin was made. Abbreviations: VHF (148-MHz radio transmitter), TDR (VHF transmitter plus a time-depth recorder), VT (visual tag-rototag).

Table S2. Summary of sets and tagging and tracking operations during 1993. The bold-faced dolphin identification numbers indicate that the dolphin was the focal animal at that time. Dolphin identification numbers with an asterisk indicate that a calf was associated with the female. "Missed" indicates that an unsuccessful attempt to recapture the focal dolphin was made. Abbreviations: VHF (148-MHz radio transmitter), TDR (VHF transmitter plus a time-depth recorder).

Table S3. Summary of sets and tagging and tracking operations during 2001. The bold-faced dolphin identification numbers indicate that the dolphin was the focal animal at that time. Dolphin identification numbers with an asterisk indicate that a calf was associated with the female. "Missed" indicates that an unsuccessful attempt to recapture the focal dolphin was made. Abbreviations: VHF (148-MHz radio transmitter), TDR (VHF transmitter plus a time-depth recorder), TDVR (VHF transmitter plus a time-depth-velocity recorder), ST (satellite tag), BT ("bullet" tag with VHF transmitter), VT (visual tag-rototag or Dufflex tag). 